PAIM, M. A. S.; PRUD'HOMME, M. S. Particularidades na escrita matemática de profissionais da construção civil

\title{
PARTICULARIDADES NA ESCRITA MATEMÁTICA DE PROFISSIONAIS DA CONSTRUÇÃO CIVIL ${ }^{1}$
}

\author{
Márcio Antônio Souza Paim ${ }^{2}$ \\ Márcio da Silva Prud'Homme ${ }^{3}$
}

\begin{abstract}
RESUMO
Este trabalho tem o objetivo de analisar os registros de escrita matemática de três profissionais da construção civil. Investiga quais são os conhecimentos matemáticos que os mesmos utilizam ao resolver uma atividade que simula o assentamento de cerâmicas numa área retangular. Ao observar os registros de escrita dos trabalhadores percebeu-se os diferentes caminhos tomados para se resolver a mesma atividade. O contato com os profissionais envolvidos mostrou que as histórias de vida de cada um foram influenciadas por problemas sociais. Por meio de uma pesquisa participante foi possível compreender melhor a maneira como cada profissional resolveu o problema proposto. Constatou-se também que o tempo escolar de cada um influenciou na execução da atividade.
\end{abstract}

Palavras-chave: Registros de escrita matemática. Profissionais da construção civil. Pesquisa participante.

\section{INTRODUÇÃO}

O saber é o resultado do conhecimento humano produzido por uma sociedade que se desenvolve ao longo dos anos. São conteúdos passados de geração em geração, ora, por meio da escola, ora, pelo ambiente que se encontra fora dela. E é dentro desse contexto que os saberes matemáticos de pessoas que se encontram distantes do meio escolar merecem a sua devida atenção.

Carpinteiros, mestres de obra e vendedores informais são exemplos de trabalhadores que pertencem a uma classe social menos favorecida da sociedade, distantes do meio

\footnotetext{
${ }^{1}$ Como citar este artigo:

PAIM, M. A. S.; PRUD'HOMME, M. S. Particularidades na escrita matemática de profissionais da construção. ForScience: revista científica do IFMG, Formiga, v. 4, n. 2, e00192, jul./dez. 2016.

${ }^{2}$ Mestrando em Gestão e Tecnologias Aplicadas à Educação (GESTEC). Possui graduação em Licenciatura em Matemática pela Universidade Federal da Bahia. Atualmente é Professor de Matemática do Ensino Básico Técnico e Tecnológico do IFBA no campus de Santo Amaro, Bahia. (http://lattes.cnpq.br/2175718630649229). E-mail: maspaim@hotmail.com.

3 Estudante da $3^{\text {a }}$ série do ensino médio em Eletromecânica do IFBA, campus de Santo Amaro. E-mail: marcioprudhomme@gmail.com.
} 
acadêmico, que possuem ricas experiências de vida. Muitos não tiveram a oportunidade de frequentar uma escola. Alguns, por serem atualmente bem idosos, apresentam limitações físicas e não possuem mais forças para voltar à sala de aula. Mesmo assim, todos trazem consigo um tipo de aprendizado.

São conhecimentos próprios do senso comum, conhecimentos empíricos que não podem ser desprezados e fazem parte da história de indivíduos inseridos na sociedade. Neste caso, surge uma matemática popular que procura atender as suas reais necessidades quando, por exemplo, se configura na compra e venda de mercadorias e porções de frutas nas feiras livres, nos supermercados das cidades ou se faz presente no raciocínio de um morador durante a pintura de uma parede e construção de uma casa. Do ponto de vista social, é comum observarmos nos bairros populares de uma cidade, construções e pavimentações de residências feitas pelos próprios moradores, que, muitas vezes, não possuem condições econômicas para a contratação de um engenheiro ou de um profissional da construção civil adequado para a realização dessa tarefa.

Logo, devido à utilização de cálculos peculiares, algumas pessoas que residem nestes locais acabam apresentando dificuldades de escrita matemática quando tentam resolver seus problemas diários à curto prazo. É refletindo sobre isso que o presente trabalho tem o objetivo de discutir sobre registros de escrita matemática desenvolvidos por trabalhadores autônomos da construção civil, representados, em particular, por 3 pedreiros.

O presente artigo é produto do Projeto de Incentivo à Aprendizagem (PINA) do campus do IFBA em Santo Amaro - BA, que pertence ao Política de Assistência Estudantil (PAAE) e visa auxiliar estudantes em situação de vulnerabilidade socioeconômica na melhoria dos seus estudos. No ano letivo de 2015, este projeto foi desenvolvido por um aluno da $2^{\mathrm{a}}$ série do ensino médio do curso integrado em Eletromecânica e seu orientador, ambos dessa Instituição e autores desse trabalho. O aluno bolsista investigou conhecimentos matemáticos que os trabalhadores utilizam ao resolver problemas no cotidiano das suas práticas profissionais.

Optamos pela Pesquisa Participante (PP) como uma modalidade de investigação por estarmos em contato direto com os sujeitos, indo a suas casas ou ambientes de trabalho. Brandão e Borges (2007) afirmam que nessa pesquisa há, em geral, trabalhos voltados à educação popular e realizados a serviço das comunidades, grupos e movimentos sociais populares. 
Cunha e Latini (2014) usam a PP como abordagem metodológica para o ensino de matemática e educação. Grossi (apud DEMO, 1999), define a PP como "um processo de Pesquisa no qual a comunidade participa da análise da sua própria realidade, com vistas a promover uma transformação social em benefício dos participantes [...]”. Observa-se que, ao longo dos anos, muitas dessas ideias estão sendo discutidas e postas em questão, logo, as pesquisas voltadas diretamente a essa realidade estão se salientando.

\section{DESENVOLVIMENTO E DISCUSSÕES}

Foram observadas as atividades dos profissionais da construção civil em seus locais de trabalho para um melhor aprendizado sobre essa prática. A opção levou em conta também o futuro contexto profissional do pesquisador bolsista, que trabalhou com situações que podem futuramente se apresentar em sua prática profissional.

No início do projeto, foi criada uma atividade que simulava a colocação de cerâmicas em áreas retangulares que representam o piso de uma casa. Essa questão foi escolhida por se tratar de uma situação que é costumeiramente vista na construção de uma casa. Geralmente, quando pedreiros, carpinteiros ou mestre de obras trabalham nas construções, uma das primeiras tarefas a cumprir é o assentamento de azulejos ou cerâmicas.

Os três trabalhadores da construção civil participaram dessa parte da pesquisa e, cada um ao seu modo, tinham que identificar em qual das duas áreas as cerâmicas poderiam ser colocadas sem haver quebras:

Uma loja vende cerâmicas retângulares como esta:

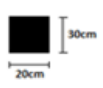

Desconsidere o rejunte e responda, justificando qual dos pisos abaixo poderia ser revestido com cerâmicas iguais a esta sem que nenhuma peça precise ser cortada. Quantas peças caberiam nesse piso?

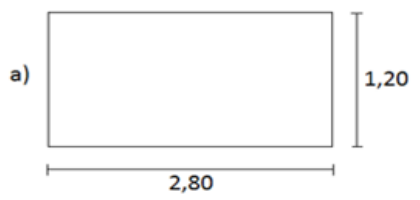

Figura 1 - Enunciado da atividade Fonte: Adaptado de Salgado e Amaral (2012).

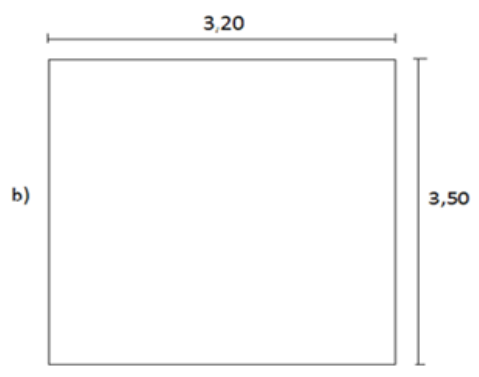

ForSci.: r. cient. IFMG, Formiga, v. 4, n. 2, e00192, jul./dez. 2016. 
Os profissionais foram escolhidos por residirem na mesma cidade de localização do campus do IFBA, isso contribuiu para a obtenção de mais dados sobre os problemas por eles enfrentadas no dia a dia. Os registros de escrita matemática dos profissionais que fizeram o exercício proposto, serviram de base para analisar as suas dificuldades com a escrita matemática. A partir disso, foram propostas maneiras adequadas na resolução do exercício.

$\mathrm{Na}$ atividade, a cerâmica tem dimensões iguais a $20 \mathrm{~cm}$ x $30 \mathrm{~cm}$ e, como a unidade de medida dos pisos não foi mostrada, o aluno bolsista do PINA teve a incumbência de explicar para cada trabalhador que as dimensões de cada piso eram dadas em metros, ou seja, $1,20 \mathrm{~m} \mathrm{x}$ $2,80 \mathrm{~m}$ e $3,20 \mathrm{~m} \times 3,50 \mathrm{~m}$, respectivamente, que também poderiam ser transformadas em centímetros: $120 \mathrm{~cm} \times 280 \mathrm{~cm}$ e $320 \mathrm{~cm} \times 350 \mathrm{~cm}$.

Se optassem pelo primeiro piso, para saber quantas cerâmicas iriam caber em um lado, poderiam dividir a medida de $120 \mathrm{~cm}$ por $30 \mathrm{~cm}$, resultando em 4 . Da mesma forma que, no outro lado, fariam a divisão de $280 \mathrm{~cm}$ por $20 \mathrm{~cm}$, obtendo 14 . Logo, o total de cerâmicas que caberiam no piso seria de $4 \times 14=56$.

Escolhendo o segundo piso, observariam pelo lado vertical que $350 \mathrm{~cm}: 30 \mathrm{~cm}=$ $11,66 \ldots$.., tendo uma quantidade não exata de cerâmicas (11 cerâmicas mais $0,666 \ldots$ de cerâmica), ou uma possível quebra na cerâmica para o ajuste no piso. Diante dessa situação, seria melhor que os trabalhadores optassem pelo $1^{\circ}$ piso para o assentamento das 56 cerâmicas.

Assim, a atividade foi distribuída em folha de papel ofício para que os sujeitos escrevessem todos os cálculos, mesmo que estivessem equivocados quanto aos seus registros de escrita. Procuramos observar os conhecimentos matemáticos expostos por meio destes registros.

\subsection{Registros dos participantes}

As particularidades nos registros de escrita matemática dos participantes da pesquisa e parte das informações sobre as suas histórias de vida foram coletadas e, portanto, serviram de base para algumas de nossas impressões. Os encontros foram realizados nas casas dos participantes ou nos seus ambientes de trabalho.

Por orientação, ao chegar nos locais, o bolsista se identificou para os trabalhadores como estudante da Instituição. Justificou a necessidade da coleta de informações tais como 
escolaridade, idade e disposição de filhos para a contribuição de pesquisas futuras sobre a realidade desses profissionais. Os seus registros, relatos e considerações podem ser vistos daqui em diante.

\section{a) Josafá}

Possui 54 anos de idade, tem 3 filhos e frequentou a escola até a $4^{\mathrm{a}}$ série primária. Segundo ele, as experiências que teve como carpinteiro ao longo do tempo o ajudaram na superação das suas dificuldades econômicas, conseguindo sobreviver a partir dos seus "bicos". Mesmo com pouca escolaridade, por ter "vindo da roça", respondeu a atividade de acordo com as suas experiências como trabalhador da construção civil:



Figura 2 - Escrita de Josafá Fonte: Dos autores (2016).

Primeiramente, calculou a quantidade de cerâmicas necessárias para revestir o primeiro piso sem se apropriar da divisão entre dois números. Apesar de ter respondido corretamente que a quantidade de cerâmicas necessárias para o revestimento do piso seria 56, é possível observar que escreveu: " 20 x $10+4=14$ " e "30 x 4". Entendemos que seu cálculo corresponde ao seguinte raciocínio: $20 \mathrm{~cm} \times 10+20 \mathrm{~cm} \times 4=20 \mathrm{~cm} \times(10+4)=20 \mathrm{~cm} \times 14$, que resulta no lado de $280 \mathrm{~cm}$, enquanto que $30 \mathrm{~cm}$ x 4 dá $120 \mathrm{~cm}$, sendo justamente as dimensões do $1^{\mathrm{o}}$ piso.

Por estar desde a $4^{\mathrm{a}}$ série primária distante do meio escolar, pode-se induzir que a discordância entre o seu pensamento e escrita é influenciada pela falta de uma prática escolar que relacione logicamente aquilo o que pensa e o que escreve. Conforme fez no cálculo do 
segundo piso, compreendemos que houve uma organização mais estruturada do seu pensamento e uma escrita matemática mais apropriada ao seu entendimento.

Embora não fosse preciso o cálculo do número de cerâmicas para o $2^{\circ}$ piso, tentou obter a quantidade exata de "pedras" para o revestimento, fazendo $20 \mathrm{~cm}$ x 16 pedras $=320 \mathrm{~cm}$ de um lado e $30 \mathrm{~cm} \times 11$ pedras $=330 \mathrm{~cm}$ do outro, $20 \mathrm{~cm}$ a menos de $350 \mathrm{~cm}$. Podemos ver também que hesitou em escrever $330 \mathrm{~cm}$, quase registrando $3300 \mathrm{~cm}$.

\section{b) Ronaldo}

Possui 29 anos de idade e trabalha aproximadamente 5 anos. Estudou até $8^{\mathrm{a}}$ série do ensino fundamental. Um pouco do que sabe sobre a profissão aprendeu com o pai que não possuía escolaridade. Segundo ele, além da necessidade da garantia do seu sustento, o nascimento dos filhos o encorajou a entrar neste tipo de trabalho.

Não teve dificuldades para responder a atividade, acrescentando que, no trabalho diário, a colocação dos azulejos em uma parede desnivelada e com imperfeições torna mais dificultoso a atuação do profissional. Respondeu corretamente e fez o desenho das cerâmicas no canto dos retângulos para ter certeza de que a quantidade obtida seria 14 x $4=56$.

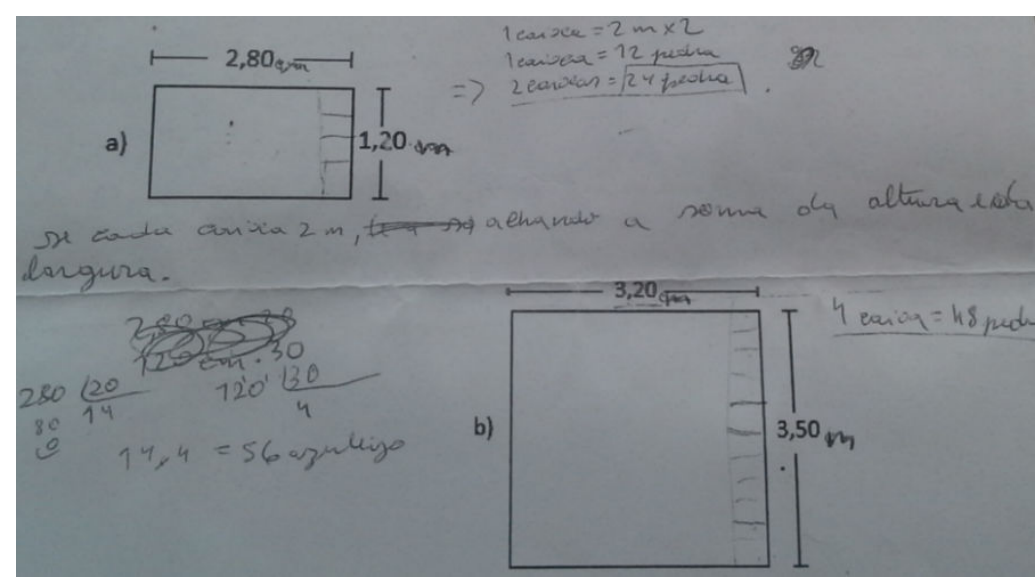

Figura 3 - Escrita de Ronaldo Fonte: Dos autores (2016).

\section{c) Antônio}

Possui 53 anos, 3 filhos e tem a pesca como outra fonte de renda. Entrou na profissão de carpinteiro para ajudar a família, já morou na rua e sempre trabalhou desde os 11 anos de 
idade. Veio morar na cidade aos 15 anos e está impossibilitado de trabalhar devido a uma queda. Mesmo assim, ainda realiza pequenos serviços que não exijam tanto esforço físico.

Não sabe ler nem escrever e estudou até segunda série primária. Não pretende voltar a escola por não ter mais disposição para o estudo. Segundo ele, a sua mente cansada não permite obter mais conhecimentos, por isso pretende continuar com as suas atividades de pesca em rios e lagos adjacentes a cidade.

Quanto ao exercício, não fez cálculos, respondeu o que lhe era conveniente através da observação visual. Achou o exercício difícil pela diferença entre as dimensões da pedra $(20 \mathrm{~cm}$ x $30 \mathrm{~cm}$ ), mas, se tivessem dimensões iguais, afirmou que ficaria mais fácil de calcular.

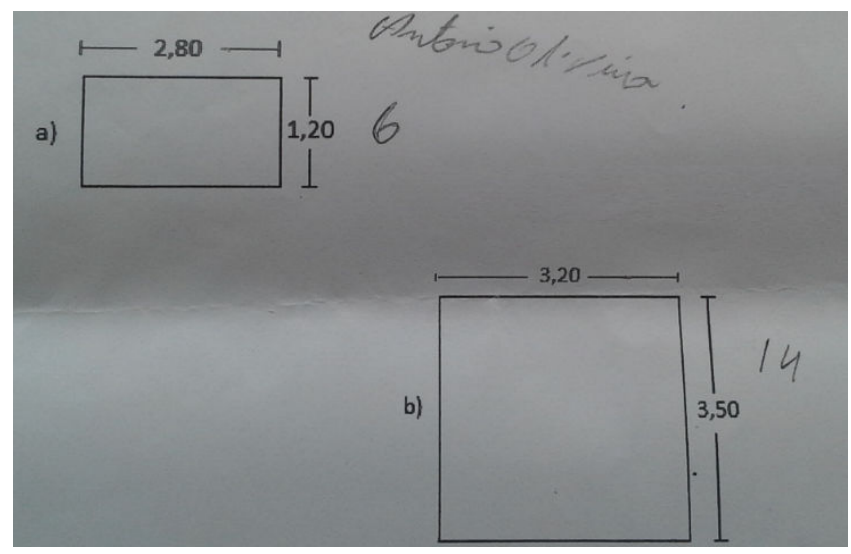

Figura 4 - Escrita de Antônio

Fonte: Dos autores (2016).

A ausência de cálculos e a dificuldade em responder ao exercício pode estar relacionada a falta de oportunidades de acesso à escola e à necessidade de sobrevivência. Conforme disse, por morar nas ruas durante um período da vida, teve que trabalhar muito cedo, não sendo possível a continuidade dos seus estudos.

\subsection{Bases para a pesquisa participante}

As fontes de conhecimento produzidas por esses profissionais constituem uma forma de conhecimento popular e também cientifico que contribuem para a ação de pesquisadores. São bases para estudo de um conhecimento espontâneo, do senso comum, que não se reduz ao tipo de ciência com características definidas pela classe dominante.

Por essa razão, os profissionais se apropriaram de linguagens comuns e escritas particulares durante a resolução do exercício. A palavra "pedra", por exemplo, foi utilizada ForSci.: r. cient. IFMG, Formiga, v. 4, n. 2, e00192, jul./dez. 2016. 
para denominar azulejos, lajotas ou cerâmicas que revestem um piso. As maneiras de responder ao problema proposto nos mostraram diferentes caminhos seguidos por cada profissional para resolver um problema de matemática básica.

As expressões matemáticas escritas por dois dos três sujeitos indicam idiossincrasias ligadas a escolaridade de cada um. A escrita matemática mostrada pelo Ronaldo aparenta ter mais clareza que a de Josafá. Isso pode ser justificado pelas suas diferentes histórias de vida, já que o primeiro estudou até a $8^{\mathrm{a}}$ série do ensino básico e o segundo até a $4^{\mathrm{a}}$.

Para Marques (2001), a escrita é uma herança do passado individual do escritor, uma linguagem autárquica que nasceu da mitologia pessoal e secreta do escritor. Com isso, é correto afirmar que, quanto maior a escolaridade do indivíduo, maior será a possibilidade de uma escrita mais legível e clara para quem lê e escreve.

A pesquisa participante se baseia na busca por estratégias de investigação e transmissão de conhecimentos aos sujeitos que mais precisam. Nesse sentido, o bolsista do projeto foi orientado a elaborar uma forma de auxiliar o Antônio a resolver a atividade, já que, por não ter escolaridade necessária, não havia respondido. Foi explicando o conceito de área que a atividade fez mais sentido para o trabalhador:

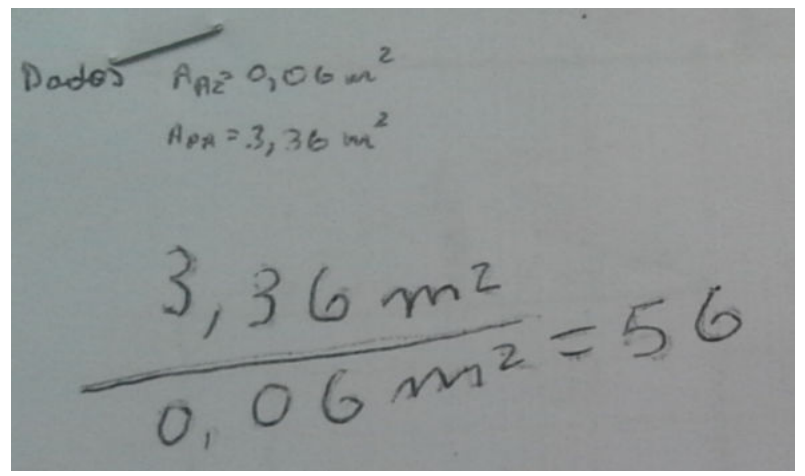

Figura 5 - Registro de Antônio após sugestão Fonte: Dos autores (2016).

Entendendo que a área do retângulo que representa a cerâmica é igual a $20 \mathrm{~cm}$ x $30 \mathrm{~cm}$ $=600 \mathrm{~cm}^{2}$ e que $600 \mathrm{~cm}^{2}$ equivale a $0,06 \mathrm{~m}^{2}$, do mesmo modo: $2,80 \mathrm{~m} \times 1,20 \mathrm{~m}=3,36 \mathrm{~m}^{2}$, efetuou a divisão simples de $3,36 \mathrm{~m}^{2}$ por $0,06 \mathrm{~m}^{2}$, totalizando 56 . Assim, ele observou que 56 "pedras" de áreas iguais a $0,06 \mathrm{~m}^{2}$ cabem numa área de $3,36 \mathrm{~m}^{2}$.

Nesse momento, o orientador e o bolsista estiveram em contato direto com o sujeito, querendo ouvir e saber se realmente a sugestão de resolução da atividade seria bem recebida por ele. E foi o que ocorreu. Para Freire (1981), o rompimento da assimetria das relações 
sociais impostas entre o pesquisador e o pesquisado; e a consideração das pessoas das bases sociais menos favorecidas como sujeitos ativos e pensantes nos esforços da pesquisa são fatores que estimulam a atuação da pesquisa participante.

\section{RESULTADOS}

Os resultados foram analisados com base na observação da participação dos envolvidos nas atividades e nas visitas em alguns dos seus locais de trabalho. As informações sobre a idade, o tempo de escola e de trabalho e sobre a realização da atividade pelos participantes foram obtidas e resumidas na TAB. 1 a seguir:

\begin{tabular}{ccccc}
\hline Participantes & Idade & $\begin{array}{c}\text { Última série } \\
\text { escolar }\end{array}$ & $\begin{array}{c}\text { Tempo de } \\
\text { profissão }\end{array}$ & $\begin{array}{c}\text { Grau de dificuldade para realizar a } \\
\text { atividade, segundo os participantes }\end{array}$ \\
\hline Ronaldo & 29 & $8^{\text {a }}$ série & $<6$ anos & baixo \\
Antonio & 53 & $2^{\mathrm{a}}$ série & $>10$ anos & alto \\
Josafá & 54 & $4^{\mathrm{a}}$ série & $>8$ anos & médio \\
\hline
\end{tabular}

Tabela 1- Dados sobre os participantes

Fonte: Dos autores (2016).

Observa-se que o Antonio, por possuir uma menor escolaridade, teve mais dificuldades em realizar a atividade. Mesmo tendo maior experiência no campo de trabalho, ainda assim é fácil de verificar a última série em que frequentou a escola. Sendo assim, constata-se que o tempo de escolaridade teve influência nos resultados, uma vez que, para os três participantes, o melhor resultado foi obtido pelo participante com maior escolaridade, neste caso, o Ronaldo.

Cada profissional da construção civil tentou resolver, a sua maneira, a atividade diretamente ligada ao seu trabalho diário. Cada um utilizou uma estratégia diferente para resolver a questão. Observando as estratégias de resolução da atividade, foi possível inferir que os trabalhadores que se encontram distantes da escola trazem consigo diferentes maneiras de pensar para uma mesma atividade proposta, os seus registros de escrita matemática são reflexos da realidade de cada um.

Há uma necessidade de mais pesquisas sobre os processos de análise e compreensão do saber popular de grupos que se encontram fora da escola, cujos saberes podem ser estudados e compartilhados para a melhoria da sua comunidade e para outros tipos de pesquisas. Neste aspecto, pensamos que a nossa pesquisa também poderá contribuir de algum modo. 


\title{
SPECIFIC WRITTEN IN PROFESSIONAL MATHEMATICS CONSTRUCTION
}

\begin{abstract}
This work aims to analyze the mathematical writing records of three construction professionals. It investigates the mathematical knowledgement they employed to solve an activity that simulates the laying of ceramic in a rectangular area. By observing the workers' written records it was realized the different paths taken to solve the same activity. The contact with the professionals involved showed that the life stories of each one were influenced by social problems. Through a participatory research it was possible to better understanding how each professional solved the problem proposed. It was also found that the school time of each one influenced the execution of the activity.
\end{abstract}

Keywords: Mathematical writing records. Professional construction. Participatory research.

\section{REFERÊNCIAS}

BRANDÃO, C. R.; BORGES, M. C. A pesquisa participante: um momento da educação popular. Revista de Educação Popular, Uberlândia, v. 6, p. 51-62. jan./dez. 2007.

Disponível em: <http://www.seer.ufu.br/index.php/reveducpop/article/view/19988/10662>. Acesso em: 3 abr. 2016.

CUNHA, A. S.; LATINI, R. M. Pesquisa participante como abordagem metodológica no ensino aprendizado de matemática e educação ambiental. Investigações em Ensino de Ciências, v. 19, n. 2, p. 323-341, 2014. Disponível em: <http://www.if.ufrgs.br/ienci/ artigos/Artigo_ID371/v19_n2_a2014.pdf>. Acesso em: 3 abr. 2016.

DEMO, P. Elementos metodológicos da pesquisa participante. In: BRANDÃO, C. R. Repensando a pesquisa participante. São Paulo: Brasiliense, 1999.

GROSSI, I. S. Mina de Morro Velho: a extração do homem: uma história, uma experiência operária. São Paulo: Paz e Terra, 1981 apud DEMO, P. Elementos metodológicos da pesquisa participante. In: BRANDÃO, C. R. Repensando a pesquisa participante. São Paulo: Brasiliense, 1999.

MARQUES, M. O. Escrever é preciso: o princípio da pesquisa. Ijuí: Unijuí, 2001.

SALGADO, M. U. C.; AMARAL, A. L. (Org.). Manual do educador: unidade formativa III. Brasília: Programa Nacional de Inclusão de Jovens e Adultos - Pró Jovem Urbano, 2012. Disponível em: $<$ http://www.gestaoescolar.diaadia.pr.gov.br/arquivos/File/pdf/ manual_educador3.pdf>. Acesso em: 3 abr. 2016.

Recebido em: 05/06/2016

Aprovado em: 09/09/2016

Publicado em: 30/09/2016 